\title{
Brainstem systems mediate the enhancement of palatability by chlordiazepoxide
}

\author{
Kent C. Berridge \\ Department of Psychology, The University of Michigan, Ann Arbor, MI 48109 (U.S.A.)
}

(Accepted 20 October 1987)

Key words: Brainstem; Benzodiazepine; Chlordiazepoxide (CDP); Feeding; Palatability; $\gamma$-Aminobutyric acid (GABA)

\begin{abstract}
Previous studies have indicated that the benzodiazepine receptor complex is involved in enhancing taste palatability after chlordiazepoxide (CDP) administration. Positive, palatability-dependent ingestive reactions elicited by orally infused tastes are facilitated in rats by CDP $(10 \mathrm{mg} / \mathrm{kg})$, and this effect is reversible by benzodiazepine antagonists. In contrast, the rats' more neutral or aversive reactions are not facilitated by CDP. Because benzodiazepine receptors exist in highest density in the forebrain, it has seemed plausible to posit forebrain structures as the locus of CDP action. However, benzodiazepine receptors do exist in the caudal brainstem (albeit in lesser density), and the ssolated decerebrate brainstem has been demonstrated to possess considerable taste processing and response capacity. The present study examined the effects of CDP on taste reactivity in chronic mesencephalic decerebrate rats. The results show that CDP can act on the subdiencephalic brainstem to enhance positive ingestive reactions even in the absence of communications with the forebrain. This indicates that both the relevant benzodiazepine receptors and the minimal neural circuit needed to modulate taste reactivity exist within or below the mesencephalon.
\end{abstract}

\section{INTRODUCTION}

Among the many well-documented effects of anxiolytic benzodiazepine administration is an increase in the ingestion of food and water ${ }^{2.5,8,9,13,24,26,32}$. Extensive work by Cooper and his colleagues and by others has made it increasingly clear that this promotion of hyperphagia does not result solely from anxiolytic effects. Instead, activation of the putative 'benzodiazepine receptor- $\gamma$-aminobutyric acid (GABA) receptor-chloride ion channel' complex appears to produce a separate enhancement of specific ingestive processes in parallel with anxiolytic action ${ }^{5-7,10,11}$, 14.29.32

Further support for the specific ingestive hypothesis has been provided recently using a taste-reactivity test ${ }^{18}$ in which natural species-typical responses, sensitive to palatability ${ }^{17}$, such as tongue protrusions, gapes, etc., are elicited from rats by infusions into the mouth through permanently implanted oral cannu- lae. Berridge and Treit ${ }^{3}$ found that chlordiazepoxide (CDP; $10 \mathrm{mg} / \mathrm{kg}$ ) increased the number of strongly ingestive responses (paw licks, lateral tongue protrusions, and rhythmic midline tongue protrusions) elicited by a variety of tastes, but had little or no effect on the number of aversive or neutrol responses elicited by the same tastes. They concluded that activation of the benzodiazepine receptor stimulated feeding in part by enhancing the positive palatability of tastes. This conclusion is compatible with the observations of Cooper and colleagues on the interactive effects of palatability and benzodiazepine-related compounds on food and fluid intake (cf. refs. 5 and 7 for reviews). Subsequently, the ability of CDP to selectively potentiate taste-elicited ingestive reactions was replicated $^{30}$ and extended to show that the effect could be prevented by concurrent administration of either the benzodiazepine antagonist, Ro 15-1788, or the inverse agonist, CGS 8216. These observations reinforced the conclusion that palatability enhanceCorrespondence: K. Berridge, Department of Psychology, The University of Michigan, Neuroscience Laboratory Building, Ann Ar-"
bor, MI 48109, U.S.A. 
ment is a consequence specifically of benzodiazepine receptor stimulation.

Relatively little is known about the location of the benzodiazepine receptors that induce feeding ${ }^{5}$. Benzodiazepine binding sites are found in highest densities in the cortex, in lesser densities in the hippocampus, corpus striatum, amygdala, thalamus, hypothalamus, and cerebellum, and in lowest densities in the brainstem ${ }^{4,31}$. Accordingly, telencephalic structures have been tentatively proposed to be the most sensitive and likely candidates for benzediazepine receptor sites involved in feeding ${ }^{5}$. This proposíion has been supported indirectly by observations that certain lesions of telencephalic structures such as basolateral amygdala, hippocampus, and caudate nucleus can produce effects on feeding similar to those produced by benzodiazepine administration (cf. ref. 5), and that forebrain microinjections of benzodiazepines can elicit behavioral effects (e.g. ref. 21).

The hypothesis that the ingestive effects of benzodiazepines are mediated by forebrain receptors is highly plausible but, in balance, a number of facts should be counterpoised against it. These are (a) that benzodiazepine binding sites can be found in the brainstem ${ }^{4}$, and their relative scarcity need not imply a lack of importance; (b) that benzodiazepines facilitate GABA transmission, which has been implicated in feeding for midbrain and hindbrain sites such as the ventral tegmentum (A10), substantia nigra, and superior colliculus ${ }^{25.27 .28}$, and that GABA transmission in such structures also has been suggested to be an output link in the control of feeding by forebrain dopamine manipulations (e.g. ref. 25); and (c) that the subdiencephalic brainstem, isolated from the forebrain in decerebrate preparations, contains neural substrates for a number of the functional subcomponents of feeding, including mechanisms for taste discrimination, ingestive and aversive response generation, and the modulation of those responses based on relevant natural satiety cues or exogenous hormonal (e.g. insulin) factors ${ }^{15,19.20}$.

These points combine to suggest we should give serious attention to the possibility that benzodiazepineinduced feeding is mediated at least in part by bra ${ }^{\circ}$ stem systems. In particular, we can ask whether: ie apparent enhancement of positive taste palatability by CDP can be mediated through brainstem receptors and processing systems on their own. This ques- tion is answerable through the ingestive/aversive taste-reactivity paradigm, which can be used even with aphagic decerebrate preparations that lack a functioning forebrain ${ }^{19}$. The present study used the chronic mesencephalic decerebrate preparation developed by Grill and Norgren ${ }^{19}$, in which a complete transection isolates the subdiencephalic brainstem at the rostral border of the superior colliculus from all communication with the forebrain, to ascertain whether the combined neural circuitry of the midbrain and hindbrain by itself is sufficient to mediate the enhancement of ingestive iaste-elicited responses that follows CDP administration.

\section{MATERIALS ANU METHODS}

Ten male Sprague-Dawley rats (300-350 g) were made decerebrate at the mesencephalic level and implanted with oral cannulae using the 2-stage procedure of Grill and Norgren ${ }^{10}$. An additional 6 rats were implanted with cannulae only and used as neurological intact controls. In the first stage of decerebration, rats were anesthetized with ketamine (100 $\mathrm{mg} / \mathrm{kg}$ ) and acepromazine $(1 \mathrm{mg} / \mathrm{kg})$, and pretreated with atropine sulfate $(1 \mathrm{mg} / \mathrm{kg})$. The dorsal skull was exposed, and a $1 \mathrm{~mm}$ wide slit in the skull was drilled unilaterally from the lateral border of the skull to within $1 \mathrm{~mm}$ of the midline. This slit was positioned rostral to lambda $40 \%$ of the distance between bregma and lambda. The dura was opened, and an Lshaped spatula was inserted into the slit with the foot of the $\mathrm{L}$ facing medially. This spatula was moved in an up-and-down motion from the midline to the lateral border and back, severing all tissue lateral to the midline but not puncturing the midline sagittal sinus. The skull slit was filled with Gelfoam and the wound was closed. In stage 2, after a 10-day recovery period, this procedure was repeated on the other side. At this time, all rats were implanted with bilateral oral cannulae $^{18}$. The cannulae entered the head dorsally, where they were anchored to the skull with stainless steel screws and acrylic cement. They then entered the mouth just lateral to the first maxillary molar. Fine tubing (PE 10) can be fitted inside the cannulae. which allowed the infusion of taste solutions.

\section{Decerebrate maintenance}

Beginning the day after surgery, decerebrates re- 
ceived 3 daily gastric intubations of a liquid diei $(50 \%$ sweetened condensed milk diluted with water, plus a vitamin supplement). Intubation was performed with an infant feeding tube; volume began at $6 \mathrm{ml}$ and ascended over the first two days to $12 \mathrm{ml}$ per meal. Rectal temperature was recorded 3 times a day, and temperature was maintained between 32 and $37^{\circ} \mathrm{C}$ by evaporative cooling or heating under a lamp. Bicillin was administered prophylactically every 3 days.

\section{Taste stimuli and drug administration}

Phase 1. On days 15-17 after surgery, rats received one injection per day of $10 \mathrm{mg} / \mathrm{kg}$ CDP to habituate to sedative effects. To accommodate the special limitations of decerebrates, a few modifications were made in the original CDP taste-reactivity procedure used by Berridge and Treit ${ }^{3}$.

Testing during phase 1 was carried out on days 18-21. Rats were tested once per day and received the taste infusion $\mathbf{3 0} \mathrm{min}$ after an injection of either isotonic saline $(1 \mathrm{ml} / \mathrm{kg}$, i.p.) alone or of CDP (10 $\mathrm{mg} / \mathrm{kg}$ ) dissolved in saline. Every rat was tested twice in both the CDP and saline condition, to reduce variability in the baseline rate of ingestive responses, and the concentration of the oral sucrose infusion was raised to $0.3 \mathrm{M}$ (from the 0.03 concentration of the original CDP study ${ }^{3}$ ) for the same reason.

Phase 2. Decerebrates surviving phase 1 were tested with two other taste stimuli of lesser palatability: $0.03 \mathrm{M}$ sucrose and $0.01 \mathrm{M} \mathrm{HCl}$. Preliminary observations in phase 1 had suggested that the sedative effects of a $10 \mathrm{mg} / \mathrm{kg}$ CDP dose were considerably pronounced in mesencephalic decerebrates compared to controls in spite of the 3-day pretreatment regimen: posture and body tone continued to be markedly relaxed by $\mathrm{CDP}$ throughout phase 1 , and righting reflexes were noticeably suppressed. For this reason, a reduced CDP dose of $5 \mathrm{mg} / \mathrm{kg}$ was added to the testing series for the two new taste stimuli, and $0.3 \mathrm{M}$ sucrose was also re-tested at this dose. All stimuli were administered twice in each drug condition in counter-balanced order. Nine decerebrates began phase 2 and 4 survived to the end of the series (day 29).

\section{Apparatus}

On each test day, a rat received its CDP or saline injection $2.5 \mathrm{~h}$ after its second feeding. Twenty-five min later, its oral cannulae were connected to a stimulus delivery tube and it was placed in a cylindrical test chamber. After $5 \mathrm{~min}$ habituation, a $0.5 \mathrm{ml}$ volume of the taste solution was infused into the mouth at a constant rate during $1 \mathrm{~min}$ (this volume was reduced from the $1.0 \mathrm{ml} / \mathrm{min}$ volume used in the original study ${ }^{3}$ in order to accommodate the reduced response capacity of decerebrate rats). The behavior of a rat was videotaped during testing via a mirror mounted beneath the transparant floor, which allowed the camera to zoom up so that the face and mouth of the rat filled the entire screen.

\section{Behavior criteria}

Each rat was scored for the occurrence of natural ingestive and aversive actions. Strongly ingestive actions are paw licking; lateral tongue protrusions (non-rhythmic) past the lip followed by forward extension, lasting about $160 \mathrm{~ms}$ (mean \pm S.E.M.); and rhythmic tongue protrusions along the midline, with a cycle length of roughly $160 \mathrm{~ms}$. A weakly ingestive or neutral component is rhythmic mouth movement at the same or lower frequency as rhythmic tongue protrusion. A behavior scored as neutral or weakly aversive is passive drip, the passive leaking of fluid from the mouth. Strongly aversive actions are gapes: large openings of the mandible and retraction of the lower lips lasting about $125 \mathrm{~ms}$; chin rubbing: bringing the mouth in direct contact with the floor and projecting the body forward; face washing: either a single wipe with the paws or a bout of several wipes; forelimb flails: shaking of the forelimb with a frequency of greater than $60 \mathrm{~Hz}$; headshaking, at greater than $60 \mathrm{~Hz}$; paw treading: planting of the forelimbs on the floor and alternating forceful strokes forward and back; and rapid locomotion about the chamber (cf. ref. 17).

\section{Videotape analysis}

Videotapes were scored at $1 / 30$ to $1 / 10$ speed by an observer blind to the drug condition of the rats. For the purpose of quantifying the number of responses emitted, discrete actions such as lateral tongue protrusions, gapes, chin rubs, and bouts of face washing, forelimb flailing, headshakes, paw treading, and locomotion were recorded each time they occurred. Continuous actions that typically persist for relatively long periods were recorded as follows: paw licks, 
mouth movements, and passive dripping were recorded in 5-s bins (any occurrence of these behaviors up to $5 \mathrm{~s}$ duration was counted as a single occur- rence). Rhythmic tongue protrusions were scored in the same way in 2 -s bins ${ }^{6}$.
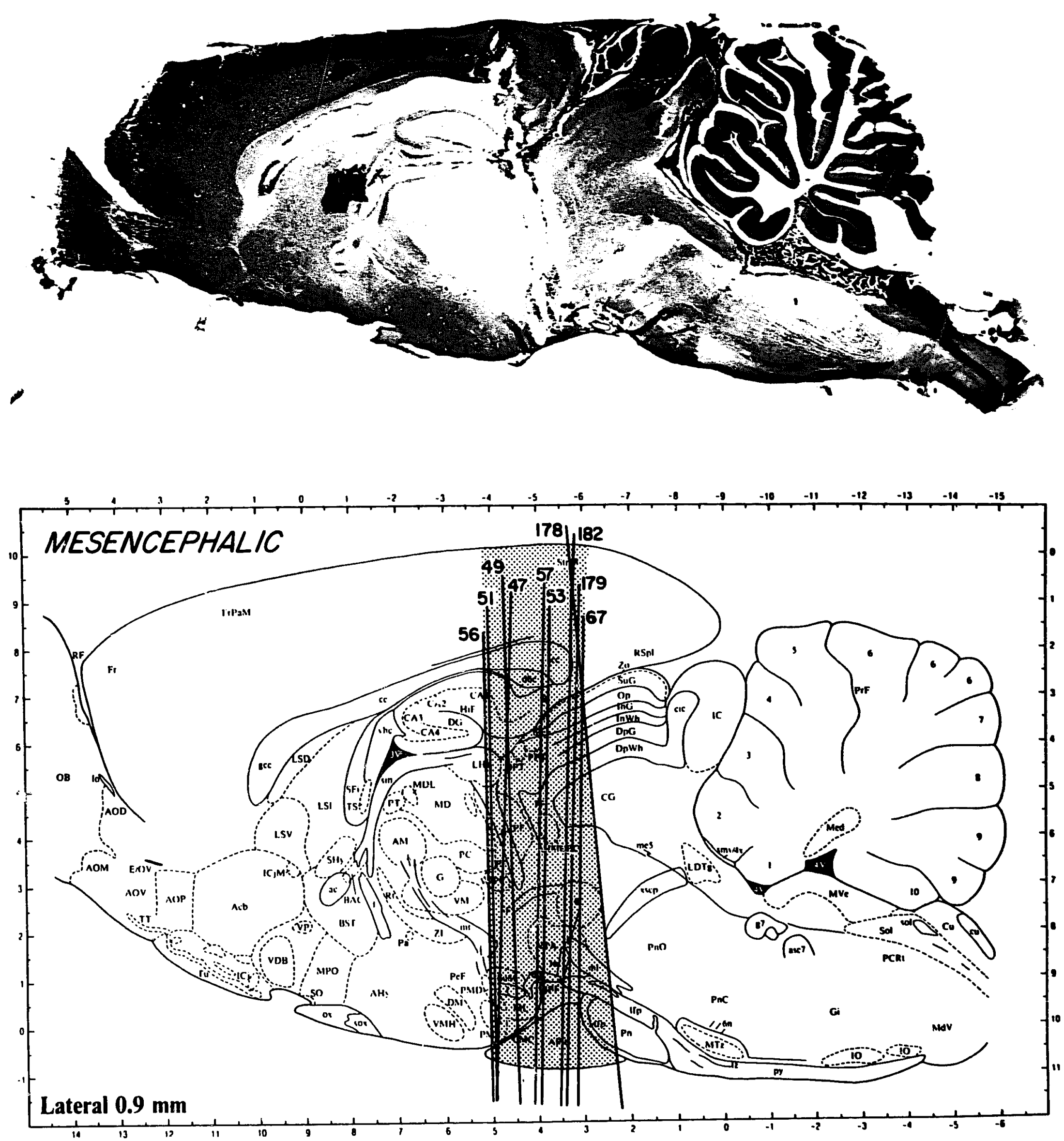

Fig. 1. A: photograph of a sagittal section from a representative mesencephalic decerebrate brain. B: range and levels of transection of individual mesencephalic decerebrate brains. Numbered lines denote the level of transection for individual rats. Atlas of Paxinos and Watson (1982). 


\section{Histology}

At the completion of the experiment, surviving decerebrates were deeply anesthetized and perfused intracardially with saline followed by formalin. The heads of rats that died before the completion of phase 2 were removed and immersion-perfused in formalin for two weeks. Brains were extracted, frozen, and sectioned in the sagittal plane. Every fourth section $(50 \mu \mathrm{m})$ was saved, slide-mounted, and stained with Cresyl violet. Completeness and placement of the transection was verified for each brain (Fig. 1).

\section{RESULTS}

An enhancement of ingestive responses to sucrose by CDP $(10 \mathrm{mg} / \mathrm{kg})$ was seen clearly in mesencephalic decerebrates during phase 1 . Natural emitted responses can be measured either in terms of response incidence (the proportion of rats showing each natural response) or response number (the mean number of responses actually emitted). Both measures showed an ingestive facilitation by CDP. In terms of response incidence, the proportion of decerebrates

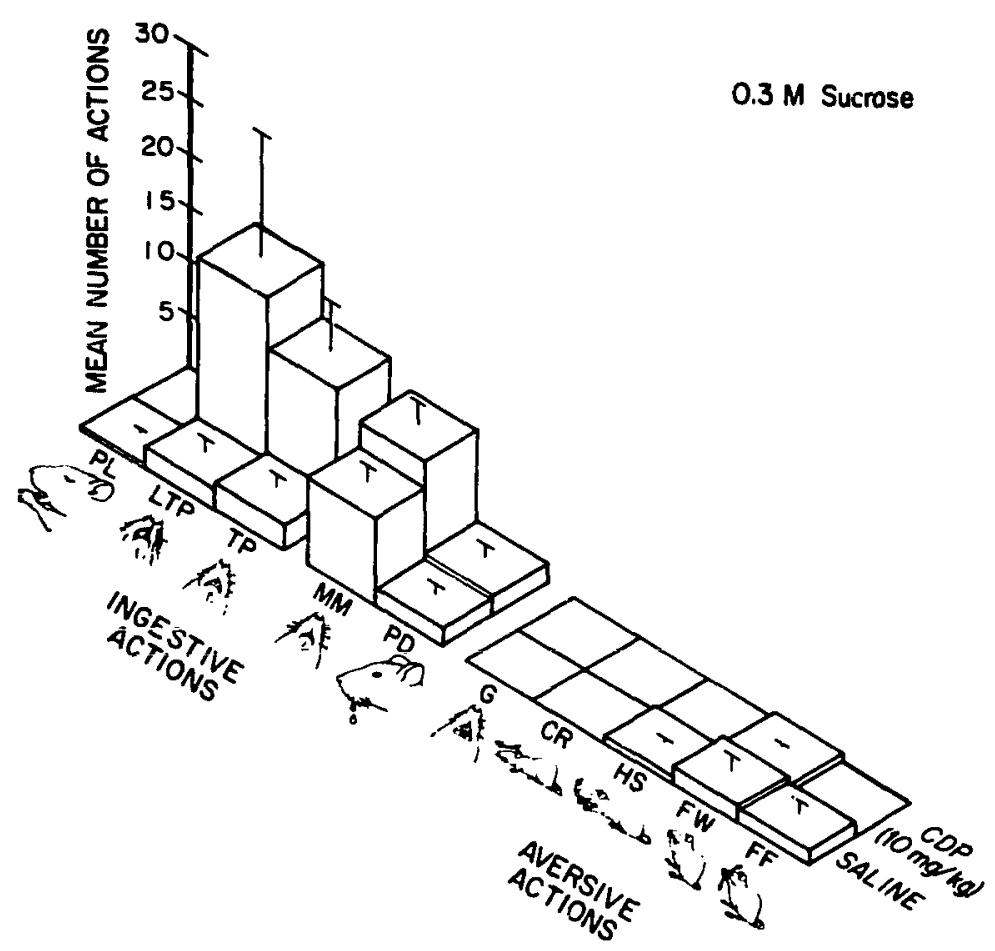

Fig. 2. Profile of phase 1 decerebrate taste reactivity. Columns denote mean number ( \pm S.E.M.) of each taste-elicited action emitted by decerebrate rats to $0.3 \mathrm{M}$ sucrose after injections of either $10 \mathrm{rig} / \mathrm{kg} \mathrm{CDP}$ (back row) or saline (front row). Ingestive actions are paw licks ( $P L)$, lateral tongue protrusions (LTP), and rhythmic tongue protrusions (TP). Neutral or compromise responses are mouth movements (MM) or passive drip (PD). Aversive actions are gapes (G), chin rubs (CR), head shakes (HS), face washing (FW), and forelimb flails (FF). that emitted ingestive rhythmic midiine tongue protrusions $(P<0.01, Z$-test of proportions) or nonrhythmic lateral tongue protrusions $(P<0.05)$ was increased after CDP $(10 \mathrm{mg} / \mathrm{kg})$. Similarly, the actual number of rhythmic tongue protrusions emitted per rat was increased after $10 \mathrm{mg} / \mathrm{kg} \operatorname{CDP}(P<0.01$, Mann-Whitney $U$ ), as was the number of total ingestive actions combined (paw licks + rhythmic tongue protrusions + lateral tongue protrusion; $\Gamma<0.02$ ). Aversive or neutral actions were not changed significantly. Fig. 2 shows the number of each action emitted to $0.3 \mathrm{M}$ sucrose after either saline or 10 $\mathrm{mg} / \mathrm{kg} \mathrm{CDP}$.

In contrast to the effects of $10 \mathrm{mg} / \mathrm{kg} \mathrm{CDP}$, no change in ingestive responses to $0.3 \mathrm{M}$ sucrose was produced by a reduced $5 \mathrm{mg} / \mathrm{kg}$ dose (Fig. 3). This pattern of a palatability enhancement at $10 \mathrm{mg} / \mathrm{kg}$ but not at $5 \mathrm{mg} / \mathrm{kg}$ also appeared to characterize the response to less palatable $0.03 \mathrm{M}$ sucrose and $0.01 \mathrm{M}$ $\mathrm{HCl}$ (Fig. 3). Intact control rats showed higher base-

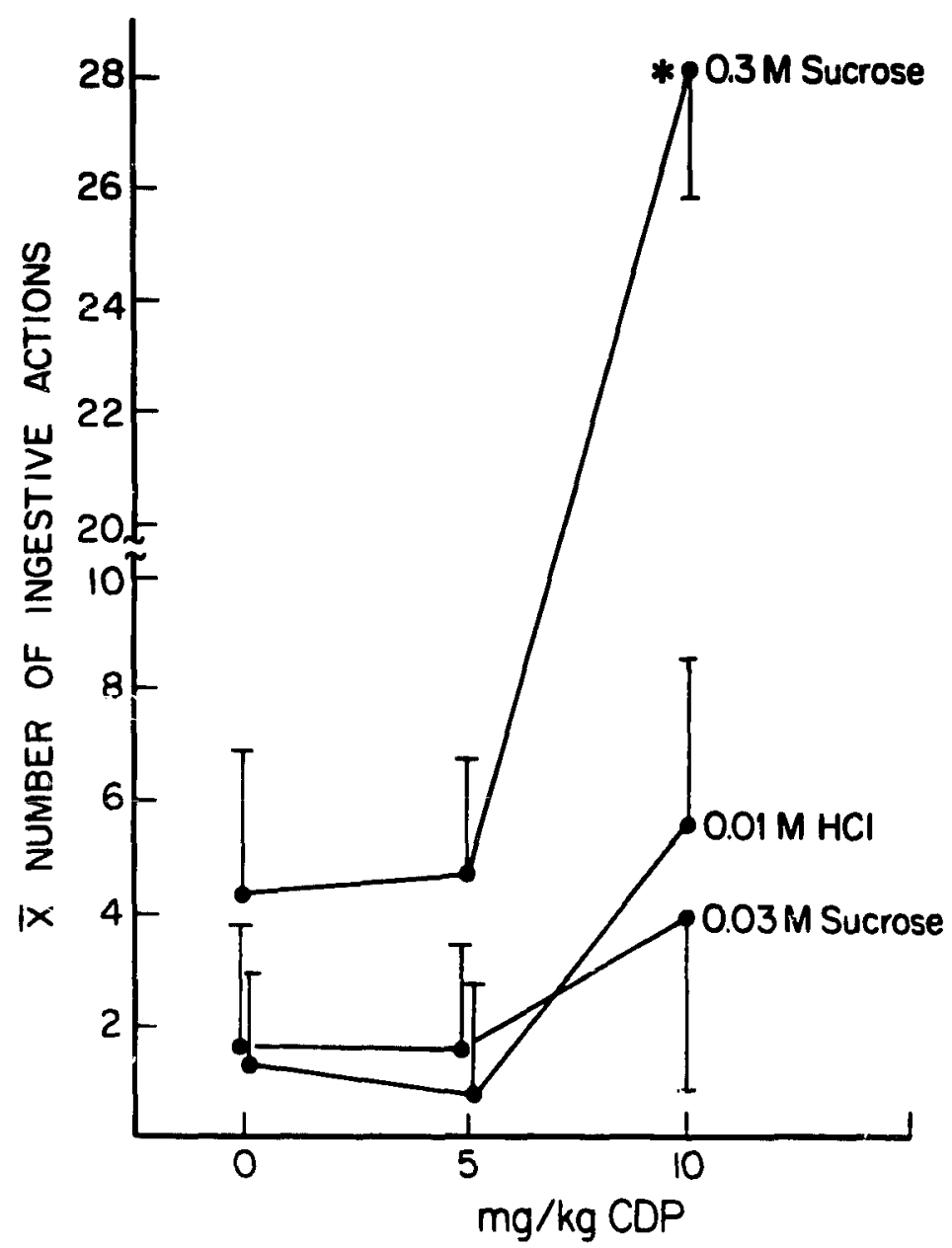

Fig. 3. Mean number ( \pm S.E.M.) of combined ingestive actions (paw licks, lateral tongue protrusions, and rhythmic midline tongue protrusions) shown by mesencephalic decrebrate rats to taste solutions. CDP dosage is plotted on the horizontal axis. Star denotes statistically significant elevation compared to saline $(0 \mathrm{mg} / \mathrm{kg} \mathrm{CDP})$ condition. 
line levels of ingestive responses than decerebrates $(P<0.05)$, but had the same pattern of CDP enhancement: ingestive responses were significantly increased to all tastes by $10 \mathrm{mg} / \mathrm{kg} \operatorname{CDP}(P<0.05$ for each) but not by $5 \mathrm{mg} / \mathrm{kg} \mathrm{CDP}$.

\section{DISCUSSION}

The midbrain and hindbrain clearly retain the capacity to increase positive taste-elicited ingestive responses in the presence of CDP $(10 \mathrm{mg} / \mathrm{kg})$ even when isolated from the forebrain by spatula transection. This implies that both the benzodiazepineGABA receptors required for palatability modulation, and the minimal neural circuits needed to translate receptor activation into effects upon behavioral responses to tastes, are contained within or below the mesencephalon.

The precise brainstem locus at which benzodiazepines might alter palatability is uncertain, but a number of possibilities exist for consideration. Influences upon feeding by the ascending mesotelencephalic dopamine system have been suggested to involve a GABA output back to the midbrain ${ }^{25.27 .28}$. Muscimol, a GABA agonist, induces feeding in satiated rats when injected into the ventral tegmental area ${ }^{1}$. Substantia nigra activity has also been iinked electrophysiologically to feeding ${ }^{23}$ and a similar promotion of feeding follows muscimol injections into the substantia nigra ${ }^{25}$. This effect is not blocked by the dopamine antagonist haloperidol but is prevented by lesions of the superior colliculus ${ }^{25}$, which receives nigrotectal projections. Dean and Redgrave ${ }^{12}$ have suggested the midbrain superior colliculus to be involved in the initiation of feeding by sensory stimuli: perioral responsiveness is altered by GABA manipulations of the superior colliculus ${ }^{25}$. It is conceivable that CDP acts upon these GABA based feeding-related circuits, which would be largely preserved in the mesencephalic decerebrate.

Raising alternative possibilities for target sites, both GABA and CDP injected into the dorsal midbrain central gray area have been reported to ameliorate the effects of aversive brain stimulation in rats ${ }^{16}$, and it is conceivable that a similar sort of meçhanism is operating here to make tastes more acceptable after CDP. It shcsld be noted, though, that the effects of CDP appear to be primarily upon the positive limb of palatability rather than upon aversion ${ }^{3.30}$ and it is possible that central gray receptors belong to a separate system from that which promotes feeding. Finally, it might be that CDP modifies palatability by acting on rhombencephalic sites below the midbrain. Benzodiazepine binding sites exist in both the pons and medulla oblongata ${ }^{4}$. The nucleus of the solitary tract of the medulla and the pontine parabrachial area contain, respectively, the first and second gustatory relay nuclei (cf. ref. 22). Future investigations should consider the possibility that taste processing might be modulated by CDP at these early stages.

Quite a separate matter from the assertion that brainstem systems suffice to mediate CDP effects upon ingestive reactions without the help of forebrain receptors or circuits, is the question of whether they actually do so in intact brains. A Jacksonian conception of hierarchial brain organization would suggest that benzodiazepines might act at multiple neural levels even to affect a single psychological or behavioral system. Different levels might control different aspects or subfunctions of the same system. The decerebrate is drastically limited in its capacities and many types $c$ behavior, including the appetitive acquisition and ingestion even of readily available food, are lost to it. The translation of the enhancement of palatability by CDP into an increase in spontaneous intake requires forebrain systems. This translation might involve forebrain benzodiazepine receptor sites as well as forebrain circlisis uctivated by brainstem sites ${ }^{5}$. The conclusion from the present study should not be that benzodiazepine effects upnn feeding are unrelated to forebrain receptors or processing circuitry, but rather that relevant receptors and circuits do exist in the brainstem, that these receptors and circuits are effective at least in modulating ingestive reactions to taste in decerebrates after chlordiazepoxide administration, and that brainstem systems must therefore be incorporated into our understanding of the control of feeding by benzodiazepines.

\section{ACKNOWLEDGEMENTS}

This work was supported by NIH grant NS 23959 to K.B. I am grateful to Ms. D. Tansil for technical assistance and to an anonymous reviewer for general comments. 


\section{REFERENCES}

1 Arnt. J. and Scheel-Kruger, J., GABA in the ventral tegmental area: differential regional effects on locomotion, aggression, and food intake after microinjection of GABA agonists and antagonists, Life Sci., 62 (1979) 51-61.

2 Bainbridge, J.G.. The effect of psychotropic drugs on food reinforced behaviour and on food consumption, Psychopharmacology, 12 (1968) 204-213.

3 Berridge, K.C. and Treit, D., Chlordiazepoxide directly enhances positive ingestive reactions, Pharmacol. Biochem. Behav., 24 (1986) 217-221.

4 Braestrup. C. and Squires, R.F., Specific benzodiazepine receptors in rat brain characterized by high-affinity ${ }^{3} \mathrm{H}$-diazepam binding, Proc. Natl. Acad. Sci. U.S.A., 74 (1977) 3805-3809.

5 Cooper. S.J.. Benzodiazepines as appetite-enhancing compounds. Appetite, 1 (1980) 7-19.

6 Cooper, S.J., $\beta$-Carbolines characterized as benzodiazepine receptor agonists and inverse agonists produce bi-directional changes in palatable food consumption, Brain Res. Bull. 17 (1986) 627-637.

7 Cooper, S.J. and Estall, L.B., Behavioural pharmacology of food, water, and salt intake in relation to drug actions at benzodiazepine receptors, Neurosci. Biobehav. Rev., 9 (1985) 5-19.

8 Cooper. S.J. and Francis, R.L., Feeding parameters with two food textures after chlordiazepoxide administration, alone or in combination with D-amphetamine or fenfluramine. Psychopharmac alogy, 65 (1979) 89-93.

9 Cooper. S.J. and Francis, R.L., Water intake and time course of drinking after single or repeated chlordiazepoxide injections, Psychopharmacology, 65 (1979) 191-195.

10 Cooper, S.J. and Gilbert, D.B., Clonazepam-induced hyperphagia in nondeprived rats: tests of pharmacological specificity with Ro 5-4864, Ro 5-3663, Ro 15-1788 and CGS 9896. Pharmacol. Biochem. Behav., 22 (1985) 753-760.

11 Cooper, S.J. and Yerbury, R.E., Midazolam-induced hyperphagia and FG 7142-induse? snorexia: behavioral characteristics in the rat, Pharmacol. Biochem. Behav., 25 (1986) 99-106.

12 Dean, P. and Redgrave, P., Dissociation of stimulationbound feeding and apomorphine-induced gnawing by lesions of the superior colliculus, Physiol. Behav., 32 (1984) 417-422.

13 Della-Ferra, M.A., Baile, C.A., McLaughlin, C.L., Feeding elicited by benzodiazepine-like chemicals in puppies and cats: structure-activity relationships, Pharmacol. Biochem. Behav., 12 (1980) 195-200.

14 Estall, L.B. and Cooper, S.J., Benzodiazepine receptormediated effect of CGS 8216 on milk consumption in the non-deprived rat, Psychopharmacology, 89 (1986) 477-479.

15 Flynn, F.W. and Grill, H.J., Insulin elicits ingestion in decerebrate rats, Science, 221 (1983) 188-190.

16 Graeff, F.G., Brandão, M.L., Audi, E.A. and Schütz, M.T.B., Modulation of the brain aversive system by
GABAergic and serotonergic mechanisms, Behav. Brain Res., 21 (1986) 65-72.

17 Grill, H.J. and Berridge, K.C., Taste reactivity as a measure of the neural control of palatability. In J.M. Sprague and A.N. Epstein (Eds.), Progress in Psychobiology and Physiological Psychology, Vol. 11, Academic Press, Orlando, 1985, pp. 1-61.

18 Grill, H.J. and Norgren, R., The taste reactivity test I: mimetic responses to gustatory stimuli in neurologically normal rats, Brain Research, 143 (1978) 263-279.

19 Grill, H.J. and Norgren, R., The taste-reactivity test II: mimetic responses to gustatory stimuli in chronic thalamic and chronic decerebrate rats, Brain Research, 143 (1978) 281-297.

20 Grill, H.J. and Norgren, R., Chronic decerebrate rats demonstrate satiation but not baitshyness, Science, 201 (1978) 267-269.

21 Nagy, J., Zambo, K. and Decsi, L., Anti-arixiety action of diazepam after intra-amygdaloid application in the rat, Neuropharmacology, 18 (1979) 573-576.

22 Norgren, R., Central neural mechanisms of taste. In I. Darian-Smith (Ed.), Handbook of Physiology: The Nervous System III, American Physiological Society, Washington, DC, 1984, pp. 1087-1128.

23 Nishino, H., Ono, T., Fukuda, M. and Sasaki, K., Monkey substantia nigra (pars reticulata) neuron discharges during operant feeding, Brain Research, 334 (1985) 190-193.

24 Randall, L.O. and Kappell, B., Pharmacology of chlordiazepoxide and analogues, Biochem. Pharmacol., 8 (1961) 15. (1961) 15.

25 Redgrave, P., Dean, P. and Taha, E.B., Feeding induced by injections of muscimol into the substantia nigra of rats: unaffected by haloperidol but abolished by large lesions of the superior colliculus, Neuroscience, 13 (1984) 77-85.

26 Riley, A.L. and Lovely, R.H., Chlordiazepoxide-induced reversal of amphetamine aversion: dipsogenic effects, Physiol. Psychol., 6 (1978) 488-492.

27 Scheel-Kruger, J., The GABA receptor and animal behavior. In S.J. Enna (Ed.), The GABA Receptors, Humana, Clifton, NJ, 1983, pp. 215-255.

28 Scheel-Kruger, J. Arnt, J., Magelund, G., Olianas, M., Przewlocka, B. and Christensen. A.V., Behavioral functions of GABA in basal ganglia and limbic system, Brain Res. Bull., 5 (1980) 261-267.

29 Treit, D., Animal models for the study of anti-anxiety agents: a review, Neurosci. Biobehav. Rev., 9 (1985) 203-222.

30 Treit, D., Berridge, K.C. and Schultz, C.E., The direct enhancement of positive palatability by chlordiazepoxide is antagonized by Ro 15-1788 and CGS 8216, Pharmacol. Biochem. Behav., 26 (1987) 709-714.

31 Williamson, M.J., Paul, S.M. and Skolnick, P., Labelling of benzodiazepine receptors in vivo, Nature (Lond.), 275 (1978) 551-553.

32 Wise, R.A. and Dawson, V., Diazepam-induced eating and lever-pressing for food in sated rats, J. Comp. Physiol. Psychol., 86 (1974) 930-941. 